\title{
Involvement of Actin Polymerization in Vesicle Recruitment at the Calyx of Held Synapse
}

\author{
Takeshi Sakaba and Erwin Neher \\ Department of Membrane Biophysics, Max-Planck-Institute for Biophysical Chemistry, Göttingen, D-37077, Germany
}

Depletion and replenishment of pools of synaptic vesicles are important determinants of short-term synaptic plasticity, but the underlying molecular mechanisms are not yet clear. As a first step toward understanding the process of vesicle recruitment, we have applied various specific agents directly to the presynaptic terminal of the calyx of Held synapse. Here we show that the nonhydrolyzable ATP analog ATP- $\gamma$ S retards the recovery from vesicle pool depletion, as does latrunculin A. Phalloidin has no effects on recovery, suggesting that dynamic actin reorganization is not necessary. Unexpectedly, neither $N$-ethylmaleimide nor staurosporine affected the recovery, calling into question the role of $\mathrm{N}$-ethylmaleimide-sensitive factor and protein kinases. The results suggest that intact actin polymerization is involved in vesicle recruitment.

Key words: synaptic transmission; synaptic depression; synaptic plasticity; vesicle pool; vesicle recruitment; actin

\section{Introduction}

In many synapses, repetitive nerve stimulation causes depression of postsynaptic responses (Elmquist and Quastel, 1965; Betz, 1970; Charlton et al., 1982; Swandulla et al., 1991). Although underlying mechanisms probably differ among different synapses and for different stimulation frequencies, it is generally accepted that depletion and replenishment of a pool of synaptic vesicles are among the crucial determinants of synaptic depression (Betz, 1970; Christensen and Martin, 1970; Rosenmund and Stevens, 1996). Biophysical concepts of vesicle pool dynamics have evolved in recent years in several CNS synapses (Borges et al., 1995; Rosenmund and Stevens, 1996; von Gersdorff and Matthews, 1997; Wu and Borst, 1999; Burrone and Lagnado, 2000). On the other hand, underlying molecular mechanisms are still unclear. Molecular dissection of physiological responses also helps to refine the models of pool dynamics postulated from biophysical analysis.

The calyx of Held allows simultaneous voltage clamp in the presynaptic and postsynaptic compartments (Forsythe, 1994; Borst et al., 1995), offering unique possibilities for combining detailed biophysical analysis and molecular perturbation. As a first step, various agents are introduced into the terminal in this study to make inferences on the mechanisms of vesicle recruitment. We have shown previously that there are two components of release at the calyx of Held that have distinct properties with respect to release and recruitment of new quanta after release. One pool, consisting of $\sim 1500$ quanta, releases rapidly (first component of release) and recovers slowly, whereas the other pool of approximately the same size releases slowly (second component of release) and recovers rapidly (Sakaba and Neher, 2001c). Recruitment of quanta to the fast pool is accelerated by

\footnotetext{
Received 0ct. 4, 2002; revised Nov. 18, 2002; accepted Nov. 19, 2002.

This study was supported in part by Deutsche Forschungsgemeinschaft Grant SFB406 (E.N.). We thank W. J. Betz, C. Rosenmund, and R. Schneggenburger for comments on the early version of this manuscript.

Correspondence should be addressed to Erwin Neher, Department of Membrane Biophysics, Max-PlanckInstitute for Biophysical Chemistry, Am Fassberg 11, Göttingen, D-37077, Germany. E-mail: eneher@gwdg.de. Copyright $\odot 2003$ Society for Neuroscience $\quad 0270-6474 / 03 / 230837-10 \$ 15.00 / 0$
}

elevated $\left[\mathrm{Ca}^{2+}\right]$ through a calmodulin-dependent process (Wang and Kaczmarek, 1998; Sakaba and Neher, 2001c). Although these properties of the fast pool provide important clues for understanding synaptic depression and recovery during highfrequency nerve stimulation (Wang and Kaczmarek, 1998), mechanisms underlying the recruitment of the slow pool were not clear at all. Therefore, the present study concentrates on possible molecular factors governing this process. Biophysical properties such as heterogeneity of release probability (Walmsley et al., 1988; Hessler et al., 1993; Rosenmund et al., 1993; Dobrunz and Stevens, 1997; Murthy et al., 1997), rapid vesicle recruitment (Burrone and Lagnado, 2000; Moser and Beutner, 2000), and $\mathrm{Ca}^{2+}$-dependent recovery from synaptic depression (Dittman and Regehr, 1998; Stevens and Wesseling, 1998; Gomis et al., 1999) are common features of CNS synapses, implying that results from the calyx synapse may be relevant to other synapses.

In this study we demonstrate that recovery of both the first and second components of release is an ATP-dependent process. Furthermore, we show that an intact filamentous actin network is involved in rapid recovery of the second component as well as the initial phase of recovery of the first component of release. $N$-ethylmaleimide (NEM) is known to disrupt the function of $\mathrm{N}$-ethylmaleimide-sensitive factor (NSF), an ATPase considered to be an important element in vesicle docking and fusion. Interestingly, NEM had no effect on vesicle recruitment. Likewise, staurosporine had no effects on recovery, excluding possible roles of protein kinases, which are major elements of ATPdependent signaling cascades. Thus, our results show that actin polymerization plays an important role in vesicle recruitment at the calyx of Held synapse. We also discuss possible schemes of vesicle pools that explain the present results.

\section{Materials and Methods}

Electrophysiology. Transverse brainstem slices (150-200 $\mu \mathrm{m}$ thick) were prepared from 8- to 11-d-old Wistar rats (Forsythe, 1994; Borst et al., 1995; von Gersdorff et al., 1997). The standard extracellular solution contained (in mM): $125 \mathrm{NaCl}, 2.5 \mathrm{KCl}, 2 \mathrm{CaCl}_{2}, 1 \mathrm{MgCl}_{2}, 25$ glucose, 25 $\mathrm{NaHCO}_{3}, 1.25 \mathrm{NaH}_{2} \mathrm{PO}_{4}, 0.4$ ascorbic acid, 3 myoinositol, and $2 \mathrm{Na}-$ 

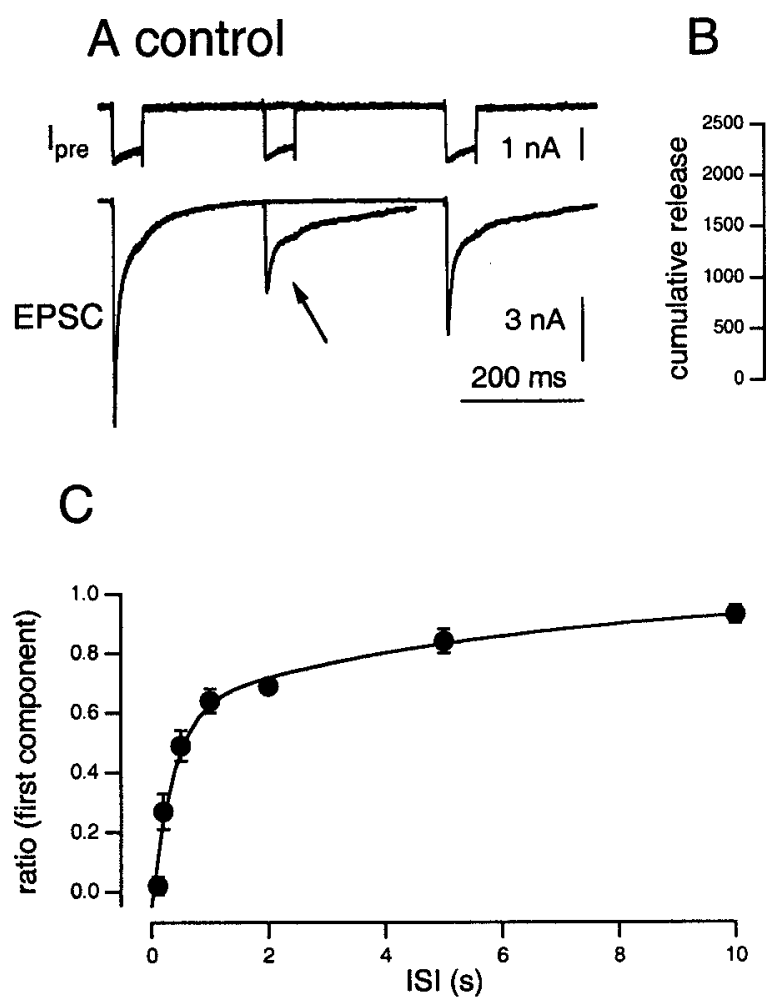
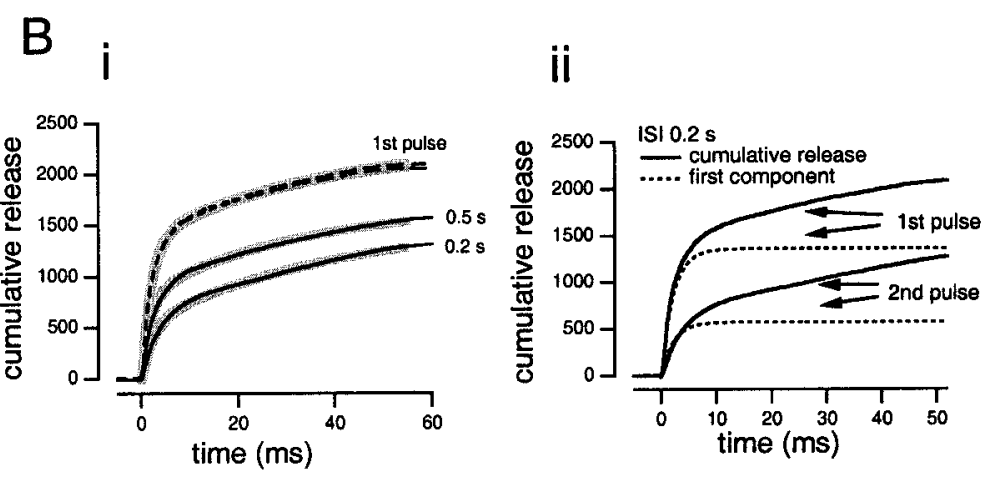

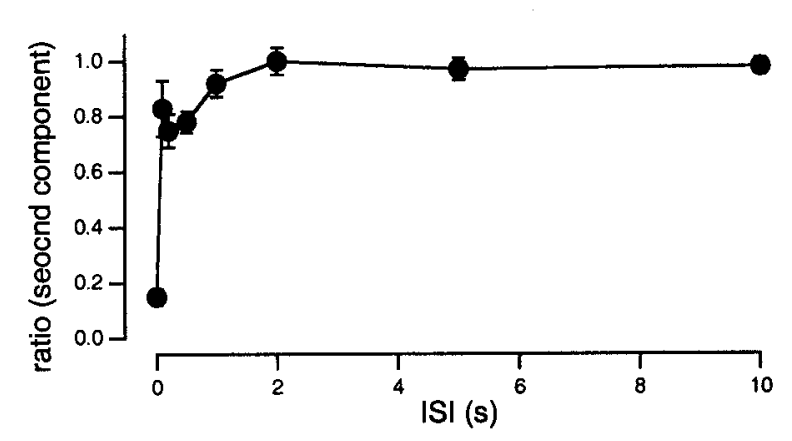

Figure 1. Recruitment of synaptic vesicles after depletion at the calyx of Held. $A$, Presynaptic pipette solution contained $0.5 \mathrm{~mm}$ EGTA to separate the first and second components of release. The dual pulse of $50 \mathrm{msec}\left(\right.$ to $0 \mathrm{mV}$ ) was applied at different intervals (200 and $500 \mathrm{msec}$ shown in this figure) to the presynaptic terminal. Presynaptic calcium currents $\left(I_{\text {pre }}\right)$ and EPSCs are shown. Bi, Cumulative release estimated from the deconvolution method is shown. Dotted traces were obtained from the first pulses, and solid traces were from the second pulses. Double-exponential fits are superimposed as gray traces. Bii, Estimation of the amount of the first and second components. Solid traces show cumulative release from the double-pulse protocol (1st pulse, first pulse; 2nd pulse, second pulse). Dotted traces show the time course of the first component estimated from a double-exponential fit. An interval of the two pulses was $200 \mathrm{msec}$. C, D, The time course of recovery of the first $(C)$ and second $(D)$ component of release during the second pulse was plotted against the interval of the two pulses. Amplitude ratios for each component between the two pulses were calculated (left axis). The first and second components were estimated by fitting double exponentials to the cumulative release plots ( $B$, gray traces). In $C$, the recovery time course of the first component was fitted with a double exponential [time constants of $376 \mathrm{msec}(66 \%)$ and $6 \mathrm{sec}$. In D, data points were connected with a line.

pyruvate, $\mathrm{pH} 7.4$ (gassed with $95 \% \mathrm{O}_{2}, 5 \% \mathrm{CO}_{2}$ ). During recordings, 1 $\mu \mathrm{M}$ TTX, $10 \mathrm{~mm}$ TEA-Cl, and $50 \mu \mathrm{M}$ D-AP5 were added to isolate presynaptic $\mathrm{Ca}^{2+}$ currents and postsynaptic AMPA receptor-mediated EPSCs. Cyclothiazide (CTZ) (100 $\mu \mathrm{M})$ and kynurenic acid (1 mM) were added to block desensitization and possible saturation of AMPA receptors and also to avoid voltage-clamp errors. A calyx of Held and the postsynaptic medial nucleus of the trapezoid body principal neuron were whole-cell clamped at $-80 \mathrm{mV}$ with an EPC9/2 amplifier (Heka, Lambrecht, Germany). The presynaptic patch pipette (3-5 M $\Omega$ ) solution contained (in mM): 135 Cs-gluconate, 20 TEA-Cl, 10 HEPES, $5 \mathrm{Na}_{2}$-phosphocreatine, 4 MgATP, 0.3 GTP, and 0.5 EGTA, pH 7.2. EGTA (0.5 mm) was also included to separate the two components of release, possibly by blocking overlapping facilitation; $0.5 \mathrm{~mm}$ EGTA is also high enough to keep resting $\mathrm{Ca}^{2+}$ concentration to a low level, according to the study of presynaptic $\mathrm{Ca}^{2+}$ regulation by Helmchen et al. (1997). According to Helmchen et al. (1997), an action potential, which carries an influx of 1 pC of $\mathrm{Ca}^{2+}$ influx, increases the average $\left[\mathrm{Ca}^{2+}\right]$ in the terminal by $400 \mathrm{~nm}$ at an endogenous $\mathrm{Ca}^{2+}$-binding ratio of 40 . The $50 \mathrm{msec}$ depolarization (see Fig. 1) induced a $\mathrm{Ca}^{2+}$ influx of $\sim 60 \mathrm{pC}$, which can saturate accordingly $960 \mu \mathrm{M}$ of high-affinity buffer. Therefore, $0.5 \mathrm{~mm}$ EGTA, which is present in the terminal, will be saturated, and $\left[\mathrm{Ca}^{2+}\right]$ will be significantly higher than the dissociation constant of EGTA at the end of a 50 msec depolarization in Figure 1. In the case of Figure $1 A$, the data of Helmchen et al. (1997) would predict that $\left[\mathrm{Ca}^{2+}\right]$ overshoots and returns to values $\sim 0.5$ $\mu \mathrm{M}$ within several hundred milliseconds. In some experiments, ATP- $\gamma \mathrm{S}$ was substituted for ATP, and the Mg concentration was kept to $4 \mathrm{~mm}$ (see Fig. 2). The presynaptic series resistance (5-20 M $\Omega$ ) was compensated by $30-90 \%$. The postsynaptic pipette $(2-3.5 \mathrm{M} \Omega$ ) contained the same solution as the presynaptic pipette, except that EGTA was increased to $5 \mathrm{~mm}$.
The postsynaptic series resistance (3-8 M $\Omega$ ) was compensated by the amplifier so that the remaining resistance was below $3 \mathrm{M} \Omega$. The remaining resistance was further compensated off-line. CTZ and D-AP5 were obtained from Tocris. Latrunculin A was from Biomol (Plymouth Meeting, PA). Phalloidin was from Molecular Probes (Eugene, OR). Other drugs were obtained from Sigma (St. Louis, MO). CTZ was dissolved in DMSO, the final concentration of which in the extracellular solution was $0.1 \%$. Experiments were performed within $10 \mathrm{~min}$ after the establishment of the whole-cell recording mode to avoid possible run-down of postsynaptic responses. Experiments were performed at room temperature.

The deconvolution method. Quantal release rates were estimated by the deconvolution method adapted for the calyx of Held (Neher and Sakaba, 2001a). This method assumes that the total EPSC can be separated into a residual current caused by the delayed clearance of glutamate in the synaptic cleft and a current component evoked by quantal release events. By combining deconvolution with fluctuation analysis, we have shown that this method is valid in the presence of cyclothiazide and kynurenic acid, which block desensitization and possible saturation of the postsynaptic AMPA receptors (Neher and Sakaba, 2001a,b). Quantal release rates, as determined by deconvolution, were integrated to obtain cumulative release, as displayed in the figures. Cumulative release was fitted with a double exponential to estimate the amount and the time course of the two components of release (see Figs. 1-6, gray traces in cumulative release plot). In the double-pulse protocol, the second pulse was fitted with a double exponential either by allowing for two time constants as free parameters or by fixing the time constants to the same values as used in the first pulse. Both methods gave satisfactory fits. All values are expressed as mean $\pm \mathrm{SEM}$. 
A

ATPyS, 4Ca

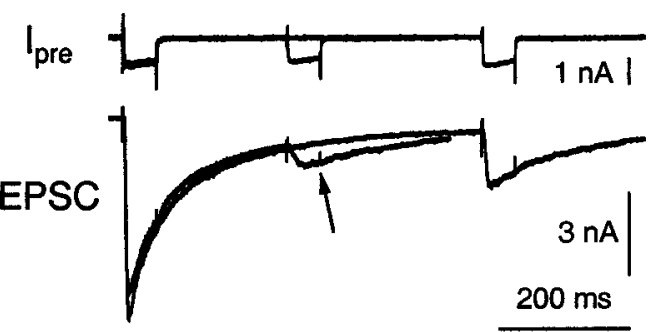

C

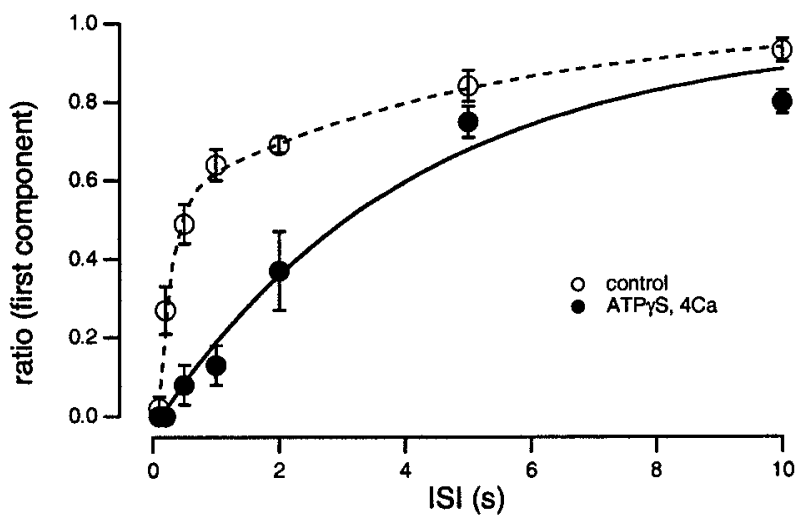

B

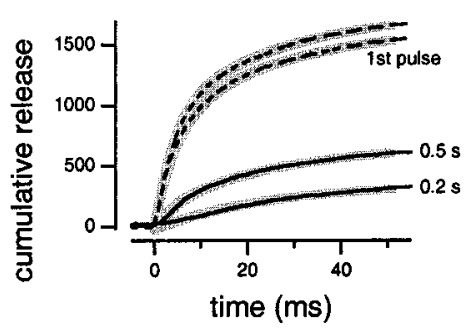

time (ms)

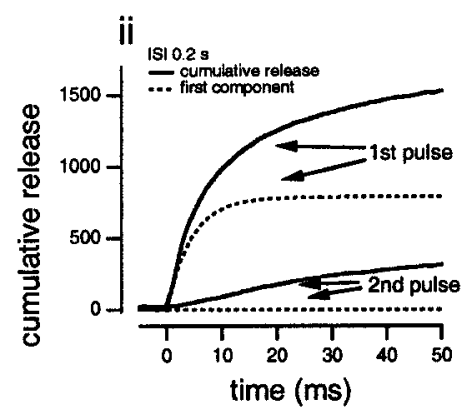

D

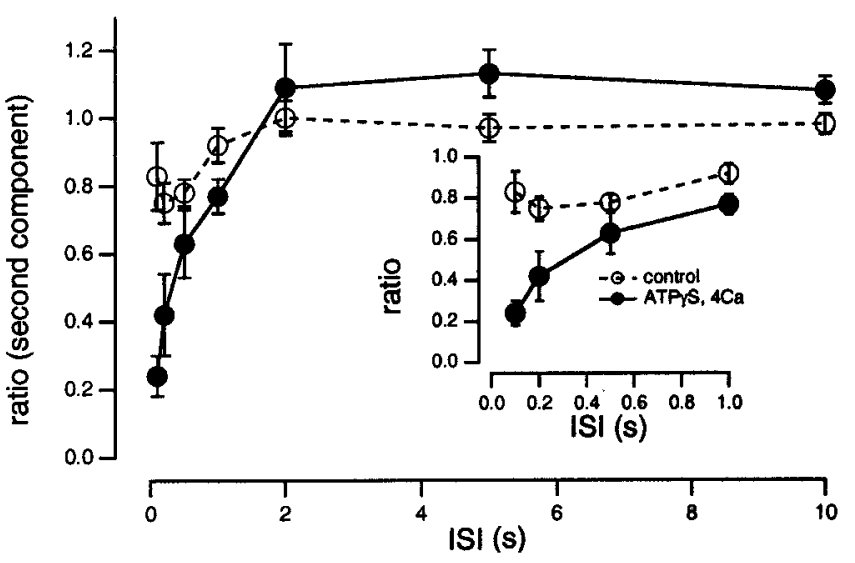

Figure 2. Effects of ATP- $\gamma S$ on vesicle recruitment. The same protocol as Figure 1, but the presynaptic pipette solution contained ATP- $\gamma$ S instead of ATP. Extracellular solution contained $4 \mathrm{~mm}$ $\mathrm{Ca}^{2+}$ to obtain a comparable amount of presynaptic $\mathrm{Ca}^{2+}$ influx. $C, D, 0$ pen symbols are from the control condition, whereas filled symbols indicate the data from ATP- $\gamma S$. C, The recovery time course under ATP- $\gamma 5$ was fitted with a single exponential (time constant of $4.0 \mathrm{sec}$ ).

\section{Results}

Depletion and recruitment of releasable quanta at the calyx of Held

In most of our experiments, $0.5 \mathrm{~mm}$ EGTA was included in the presynaptic patch pipette; this allows separation of the first and second components of release (Sakaba and Neher, 2001b). At the same time, this concentration of EGTA is high enough to clamp the resting $\mathrm{Ca}^{2+}$ concentration to a low level (Helmchen et al., 1997) for several tens of milliseconds of depolarization. Indeed, a prolonged depolarizing pulse (50 $\mathrm{msec}$ in duration) is necessary to temporally overcome the exogenous buffer (Sakaba and $\mathrm{Ne}$ her, 2001c). We applied a $50 \mathrm{msec}$ depolarizing pulse to $0 \mathrm{mV}$ to the presynaptic terminal, which almost depleted both the first and second components of release (Fig. $1 A, B$, dotted traces in the cumulative release plot). The amplitude of presynaptic $\mathrm{Ca}^{2+}$ current was $1438 \pm 81 \mathrm{pA}$. Under this condition, the fast and slowly releasing quanta are released with time constants of $1.98 \pm 0.28$ $\operatorname{msec}(53.8 \pm 2.7 \%)$ and $27.6 \pm 3.3 \mathrm{msec}(n=8)$, respectively, as determined by double exponential fits to the cumulative release time courses (Fig. 1 Bi, gray traces). Time constants varied from cell to cell, and in previous studies the ranges of the two time constants were $\sim 2-3$ and $20-30 \mathrm{msec}$, respectively (Sakaba and Neher, 2001b,c). Figure 1 Bii shows an example of how much the first component (dotted trace, first pulse) contributes to the total release (solid trace, first pulse). Differences between the two traces are mediated by the second component, which becomes prominent after prolonged stimulation.

The same pulse was applied at different interstimulus intervals (ISIs) to monitor the recovery of the two components of release
(Fig. $1 A, B$; solid lines in cumulative release plot of Fig. $1 B i$ ). Enough time between stimulus pairs $(45-60 \mathrm{sec})$ was allowed for complete recovery of quantal release between pulse pairs. The second pulse in a pair elicits slightly smaller presynaptic $\mathrm{Ca}^{2+}$ current amplitude. With an interval of $100 \mathrm{msec}$, presynaptic $\mathrm{Ca}^{2+}$ current amplitude during the second pulse was $\sim 90 \%$ $(0.88 \pm 0.03)$ of that during the first pulse. For longer intervals, the reduction was smaller. Figure $1 \mathrm{Bii}$ shows an example trace of the second pulse, which was evoked $200 \mathrm{msec}$ after the first pulse. In this example, $40 \%$ of the first component (dotted trace) recovered, and the second component (difference between the dotted and the solid trace) recovered almost completely. On average, the second component recovered $>70 \%$ within $200 \mathrm{msec}$, whereas the first component recovered more slowly (Fig. $1 B-D$ ). The first component recovered biexponentially [time constants of 376 msec $(66 \%)$ and $6 \mathrm{sec}$. Rapid recovery of the first component has been shown to be $\mathrm{Ca}^{2+} /$ calmodulin dependent (Sakaba and $\mathrm{Ne}$ her, 2001c). We also quantified the time course of recovery in each cell by measuring $t_{0.5}$ (time required for recovering $50 \%$ of the pool). In seven cell pairs, recovery of the first and second components of release had $t_{0.5}$ values of $0.56 \pm 0.12$ and $0.058 \pm$ $0.011 \mathrm{sec}$, respectively (see Fig. $4 E$ ).

\section{ATP- $\gamma$ S slows down recruitment of the slowly releasing as} well as rapidly releasing quanta

No pharmacological manipulations have been described so far that alter the recruitment of slow vesicles at the calyx synapse. In neuroendocrine cells and retinal bipolar cells, it has been shown that ATP depletion or substitution of ATP with nonhydrolyzable 

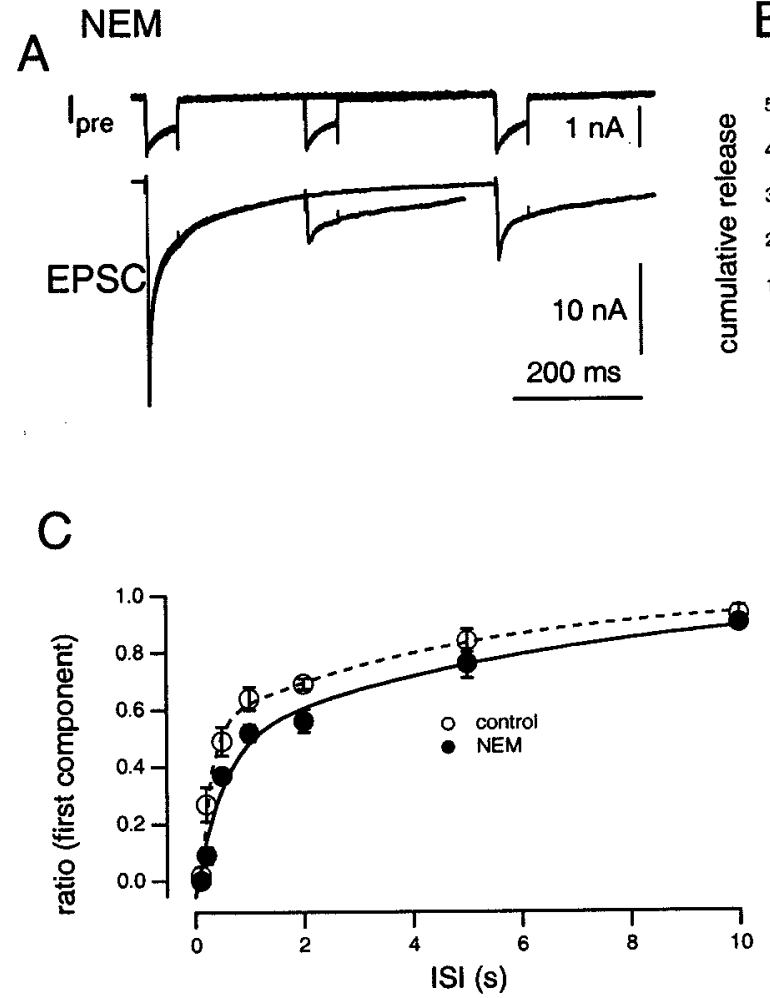
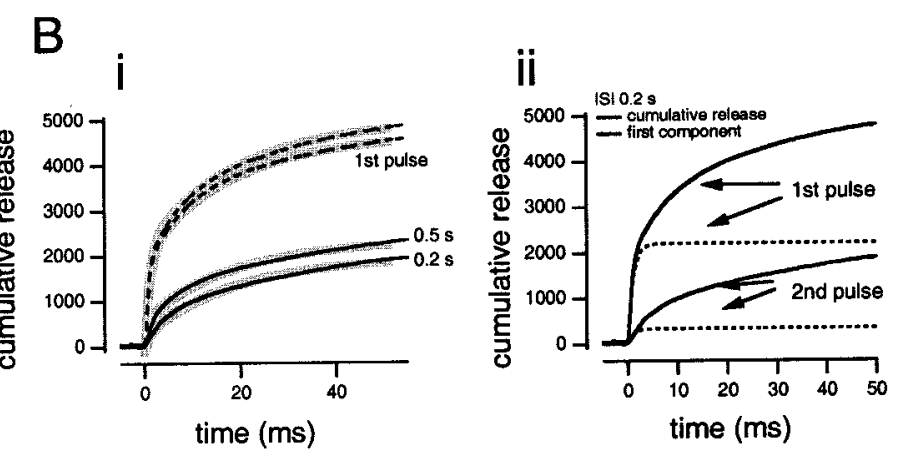

Figure 3. Effects of NEM on vesicle recruitment. The same protocol as Figure 1, but the presynaptic pipette solution contained NEM. C, D, Open symbols are from the control condition, whereas filled symbols indicate the data from NEM. C, The recovery time course under NEM was fitted with a double exponential [time constants of $483 \mathrm{msec}(53 \%)$ and 6.6 sec].

analogs blocks recruitment of secretory vesicles to the readily releasable pool (Parsons et al., 1995; Xu et al., 1998; Heidelberger, 1998; Heidelberger et al., 2002). We thus examined whether substitution of ATP with ATP- $\gamma \mathrm{S}(4 \mathrm{~mm})$ affects the recovery of the second component at the calyx of Held (Fig. 2). The total concentration of intracellular $\mathrm{Mg}$ was kept at $4 \mathrm{~mm}$, and other conditions were similar to control. In an initial set of experiments, we found that the substitution reduces presynaptic $\mathrm{Ca}^{2+}$ current amplitude $(963 \pm 55 \mathrm{pA}$ on average in ATP- $\gamma \mathrm{S}$ and $1438 \pm 81 \mathrm{pA}$ in control). This slows down the time course of release during the depolarizing pulse and renders separation of the two components of release difficult in many cases, mainly because of the steep dependence of the first component of release on presynaptic $\mathrm{Ca}^{2+}$ influx (Borst and Sakmann, 1996; Schneggenburger et al., 1999). We thus raised the external $\mathrm{Ca}^{2+}$ concentration to $4 \mathrm{~mm}$ in these experiments to obtain $\mathrm{Ca}^{2+}$ currents of comparable amplitudes in controls, and the presynaptic $\mathrm{Ca}^{2+}$ current amplitude was $1231 \pm 80 \mathrm{pA}$. The time course of release could be fitted with a double exponential with time constants of $3.42 \pm 0.36 \mathrm{msec}$ $(50.7 \pm 4.7 \%)$ and $22.3 \pm 3.7 \mathrm{msec}$, respectively (Fig. $2 \mathrm{Bi}$ ).

When dual pulses were applied in the presence of ATP- $\gamma \mathrm{S}$, the amount of recovery was significantly reduced in the second pulse (Fig. $2 A$ ). When Figures $1 A$ and $2 A$ are compared, the amplitude of EPSC is seen to be smaller at the second pulse in the presence of ATP- $\gamma \mathrm{S}$ (Figs. 1A, $2 \mathrm{~A}$, compare arrows). The rising phase of EPSCs also slowed down. Paired-pulse ratios of the presynaptic $\mathrm{Ca}^{2+}$ current amplitudes $(0.93 \pm 0.02$ with an interval of 100 $\mathrm{msec}$ ) were comparable with those of control conditions. From cumulative release (Fig. $2 \mathrm{Bi}$ ) we estimated how much of the first and second components recovered quantitatively by doubleexponential fits (gray traces). Fig 2 Bii shows in an example how much the first and second components recovered $200 \mathrm{msec}$ after the first pulse. During the second pulse, we observed no recovery of the first component (dotted trace in the second pulse); the second component recovered 44\% (compare Figs. 1 Bii, 2 Bii). Figure 2, $C$ and $D$, shows recovery time courses of the first and second components, respectively. It is seen that both components recover more slowly compared with control. On average, recovery of the first and second components had $t_{0.5}$ values of $2.83 \pm$ 0.31 and $0.43 \pm 0.06 \mathrm{sec}$, respectively (see Fig. $4 E$ ). A qualitatively similar slowing of the recovery was observed when the experiment was performed in $2 \mathrm{mM} \mathrm{Ca}^{2+}(n=9)$, although quantification was difficult because of problems in the separation of the two components of release (see above).

Because we used the $\mathrm{Li}^{+}$salt of ATP- $\gamma \mathrm{S}$ for the experiments, we also tested the effect of $\mathrm{Li}^{+}$alone. In Drosophila neuromuscular junctions, it has been shown that sustained synaptic transmission could not be maintained in the presence of $\mathrm{Li}^{+}$because of interference with inositol metabolism (Acharya et al., 1998). At the calyx of Held, $\mathrm{LiCl}$ at a concentration of $10 \mathrm{~mm}$ had no significant effect on vesicle recruitment $(n=5)$.

\section{NEM and staurosporine do not affect recruitment of releasable quanta}

Figure 2 shows that ATP hydrolysis is essential for recovery of the first and second components of release. ATP is involved in many cellular processes, including maintenance of $\mathrm{Ca}^{2+}$ channels in a functioning state. We thus made an effort to find factors that are related to ATP hydrolysis and specifically involved in the recovery of the second component. One candidate is NSF, because NEM has been shown to block recruitment of vesicles in endocrine cells (Eliasson et al., 1997; Xu et al., 1999). To test the possible involvement of NSF, we introduced NEM (1 mM) via the patch pipette and applied the same protocol as has been used in 
A

\section{latrunculin A}

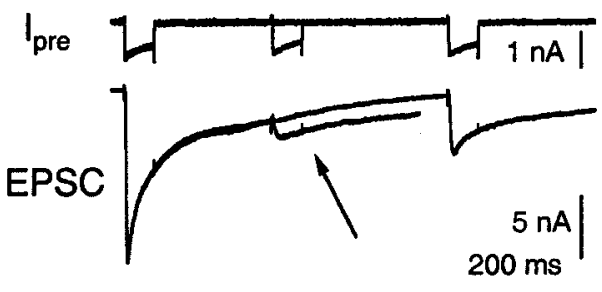

C

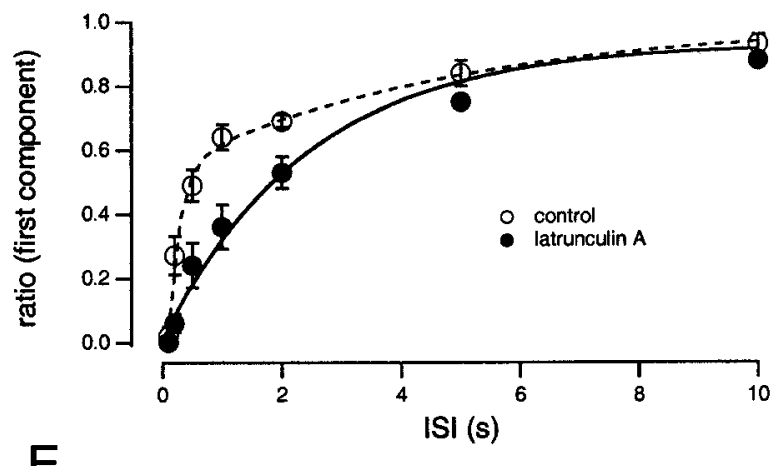

E

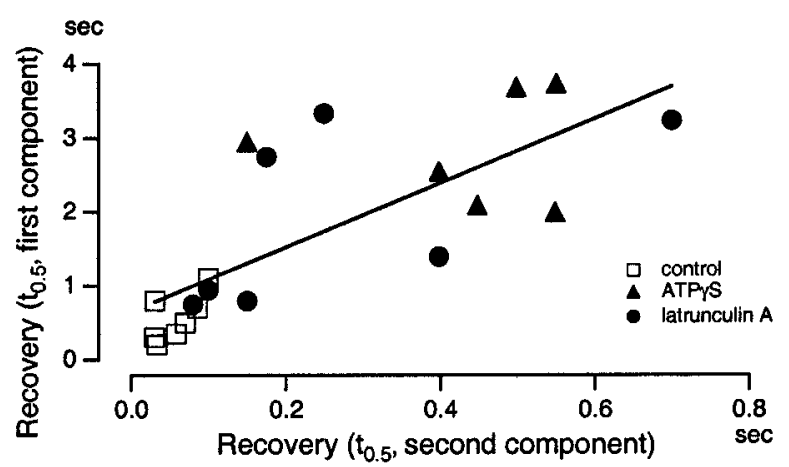

B

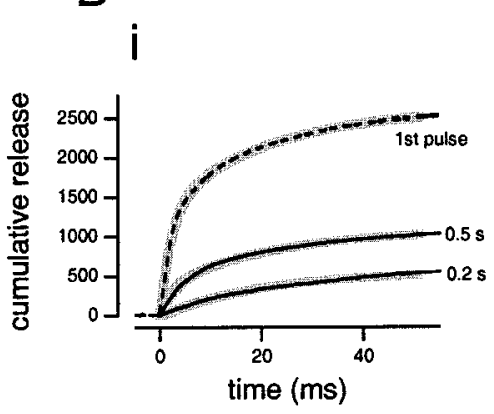

D

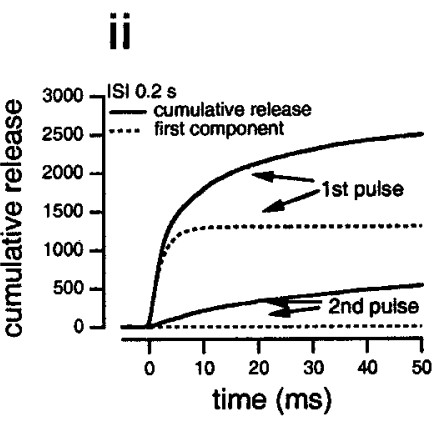


A

latrunculin $A+$ phalloidin

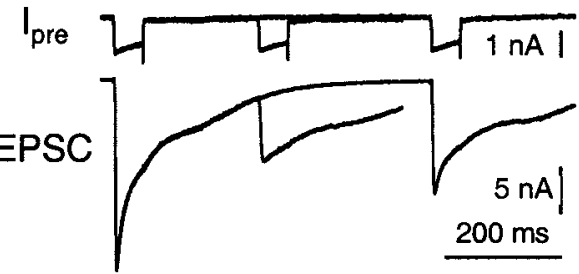

C

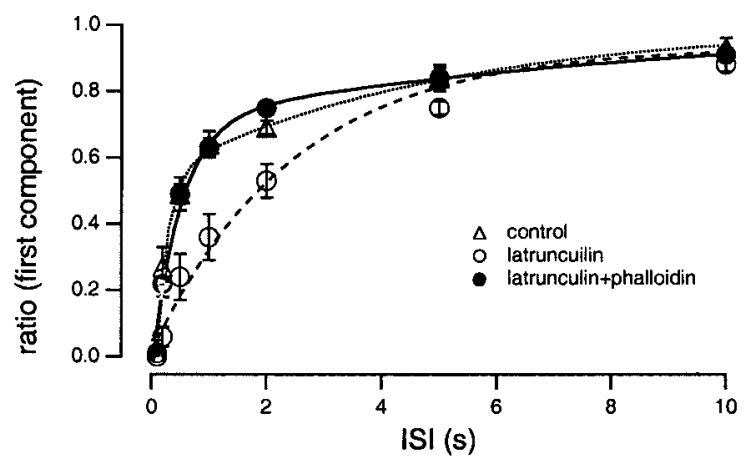

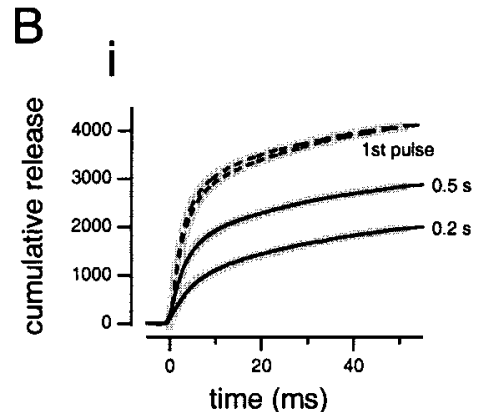

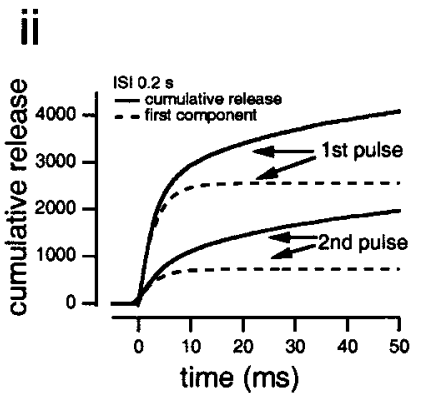

D

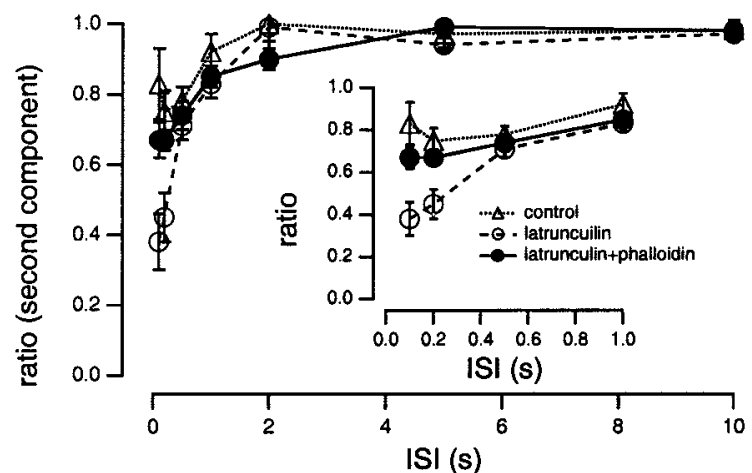

Figure 5. Effects of latrunculin $A$ and phalloidin on vesicle recruitment. The same protocol as Figure 1, but the presynaptic pipette solution contained latrunculin $A$ and phalloidin. $C, D, O p e n$ triangles are from the control condition, open circles are from latrunculin A, and filled circles are from latrunculin A and phalloidin. C, The recovery time course under latrunculin $A$ and phalloidin was fitted with a double exponential [time constants of $493 \mathrm{msec}(76 \%)$ and $8.7 \mathrm{sec}$.

aration allows direct introduction of actin depolymerizing agents and stabilizers via the patch pipette to the presynaptic terminal. Modulatory effects on quantal release can be examined in isolation while the terminal is voltage clamped and presynaptic membrane currents are monitored. Phalloidin staining showed that $\mathrm{F}$-actin is confined to the distal end of the presynaptic terminal of the calyx of Held (Saitoh et al., 2001).

Latrunculins promote depolymerization of $\mathrm{F}$-actin by binding to G-actin to form a 1:1 complex (Spector et al., 1999). We introduced latrunculin A $(25 \mu \mathrm{M})$ through the presynaptic patch pipette to examine whether this agent could mimic the effect of ATP- $\gamma S$ (Fig. 4). Dual pulses were applied to the presynaptic terminal as has been described for control experiments, and cumulative amounts of release were estimated (Fig. 4A,B). Presynaptic $\mathrm{Ca}^{2+}$ currents $(1227 \pm 70 \mathrm{pA})$ as well as their paired-pulse ratios $(0.89 \pm 0.03$; ISI $=100 \mathrm{msec})$ were similar to those of control. The time course of cumulative release could be fitted with a double exponential with time constants of $1.93 \pm 0.26$ $\operatorname{msec}(49.3 \pm 1.5 \%)$ and $21.0 \pm 3.2 \mathrm{msec}$, respectively. These values are not different from those of control experiments, which suggests that latrunculin has no augmenting effects on quantal release probability. Such an effect had been described in hippocampal cultures (Morales et al., 2001). On the other hand, during second pulses, EPSCs were much smaller; this can be seen by comparing Figures $1 \mathrm{~A}$ and $4 \mathrm{~A}$ (arrows). As a result, cumulative release was smaller (Fig. $4 \mathrm{Bi}$ ). In the case of Figure $4 \mathrm{Bii}$, the second pulse was applied $200 \mathrm{msec}$ after the first pulse. In this example, the first (dotted trace) and the second component (difference between the solid and dotted traces) recovered 0 and $42 \%$, respectively. Figure $4, C$ and $D$, shows the time course of recovery of the first and second components, and recovery of both com- ponents became slower. This result was similar to that of experiments with ATP- $\gamma S$ (Fig. 2). Recovery of the first and second components had $t_{0.5}$ values of $1.88 \pm 0.44$ and $0.26 \pm 0.08 \mathrm{sec}$, respectively (Fig. $4 E)(n=7)$.

In Figure $4 E, t_{0.5}$ values of the recovery of the first component were plotted against those of the second component in three conditions (control conditions, ATP- $\gamma S$, and latrunculin A). The data of ATP- $\gamma S$ and latrunculin A displayed a similar relationship, suggesting that both had the same effects on the recovery process. The relationship between the two quantities had a positive correlation, and the correlation coefficient was 0.75 , as estimated from the linear regression shown in Figure $4 E$. Thus, actin seems to act similarly on recovery of the two components. Interestingly, recovery of the first component had delays of $>200 \mathrm{msec}$ in four of seven pairs with latrunculin A and in all synapses with ATP- $\gamma \mathrm{S}$. In control cell pairs, the delay was always $<100 \mathrm{msec}$ (see Discussion).

In hippocampal cultures, extracellular application of latrunculin A increases miniature EPSC frequency temporally (Morales et al., 2000). In preliminary attempts, we applied latrunculin A extracellularly, but we found no increase in the mEPSC frequency. However, it is possible that latrunculin A did not rapidly and sufficiently reach the presynaptic terminal in the slice preparation.

Phalloidin is membrane impermeable and known to stabilize actin filaments and promote actin polymerization (Cooper, 1987; Sampath and Pollard, 1991). To confirm that latrunculin exerts its effect on actin filaments, we applied phalloidin (100 $\mu \mathrm{M})$ together with latrunculin A via the presynaptic patch pipette (Fig. 5). This prevented the effects of latrunculin $A$ and resulted in a normal time course of recovery of both the first and second 
A

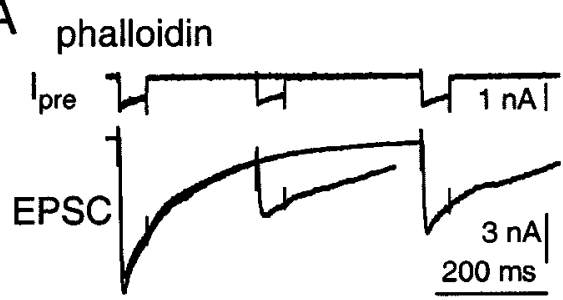

C
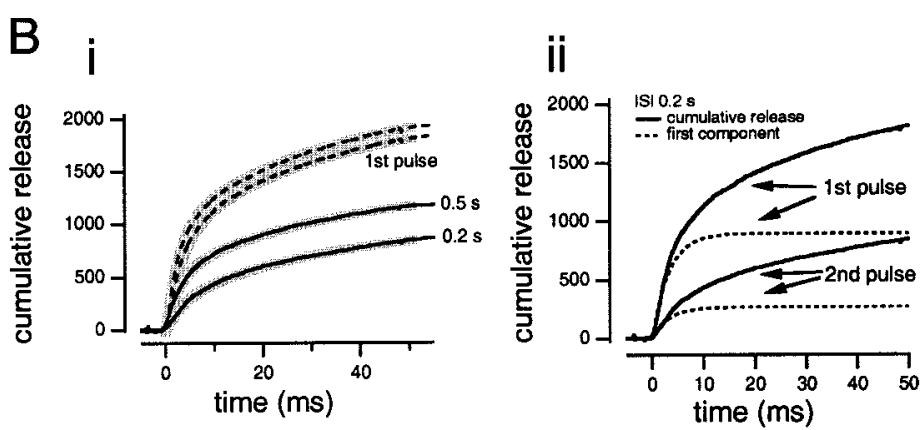

D
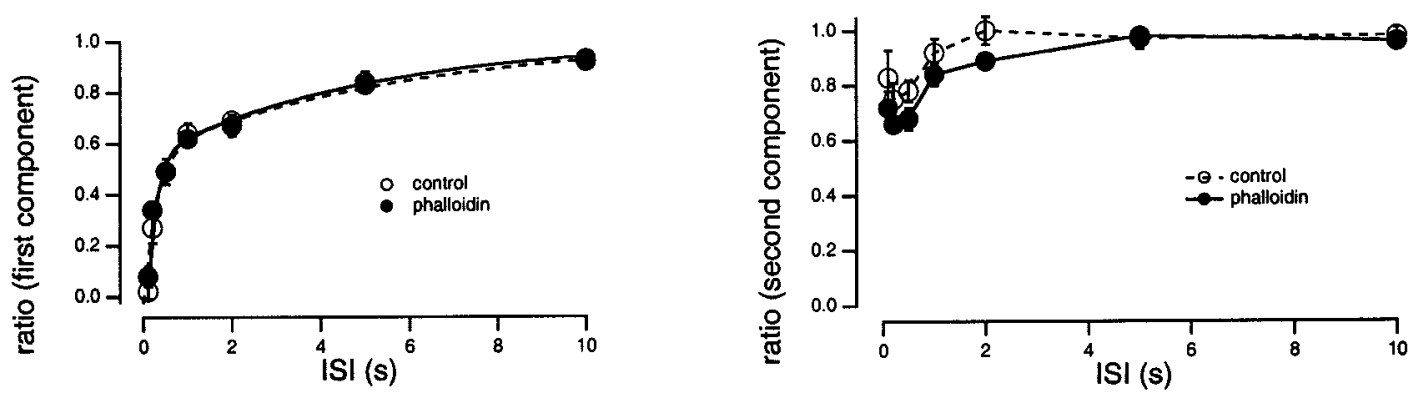

Figure 6. Effects of phalloidin on vesicle recruitment. The same protocol as Figure 1, but the presynaptic pipette solution contained phalloidin. C, D, Open circles are from the control condition, and filled circles are from phalloidin. C, The recovery time course under phalloidin was fitted with a double exponential [time constants of $283 \mathrm{msec}(58 \%)$ and $5.6 \mathrm{sec}$ ].

components (Fig. 5C,D). Recovery of the first and second components had $t_{0.5}$ values of $0.48 \pm 0.05$ and $0.077 \pm 0.005 \mathrm{sec}$, respectively $(n=8)$. The time constants of release of the fast and slow components were $2.41 \pm 0.17 \mathrm{msec}(45.2 \pm 3.1 \%)$ and $27.7 \pm 1.7 \mathrm{msec}$, respectively, and these values were not different from those during controls. Presynaptic $\mathrm{Ca}^{2+}$ currents (1491 \pm $73 \mathrm{pA})$ as well as their paired-pulse ratios $(0.87 \pm 0.04 ;$ ISI $=100$ $\mathrm{msec}$ ) were similar to those of control. The results confirm that latrunculin A acts specifically on the actin cytoskeleton.

\section{Phalloidin alone has no effects on vesicle recruitment}

It has been shown that phalloidin retards the movement of secretory granules (Lang et al., 2000; Oheim and Stühmer, 2000), which led to the suggestion that actin filaments have to be dynamically reorganized to allow granules to approach the plasma membrane. At the calyx of Held, application of phalloidin alone had no effect on recovery (Fig. 6), and $t_{0.5}$ values of the first and second components were $0.42 \pm 0.04$ and $0.071 \pm 0.005 \mathrm{sec}$, respectively $(n=9)$. Time constants of the first and second components of release during the first pulse $[2.45 \pm 0.19 \mathrm{msec}$ $(47.8 \pm 2.5 \%)$ and $29.1 \pm 2.2 \mathrm{msec}]$ were also similar to those of control experiments. Presynaptic $\mathrm{Ca}^{2+}$ currents $(1404 \pm 99 \mathrm{pA})$ as well as their paired-pulse ratios $(0.88 \pm 0.04$; ISI $=100 \mathrm{msec})$ were similar to those of control. This indicates that dynamic reorganization of actin is not necessary for vesicle recruitment at the calyx synapse.

\section{Discussion}

The results presented here show the importance of actin polymerization for recruitment of synaptic vesicles. We found that substitution of ATP with the nonhydrolyzable analog ATP- $\gamma \mathrm{S}$ slowed the recruitment of synaptic vesicles (Fig. 2). In the subsequent sets of experiments, we made an attempt to identify the ATP-dependent process more specifically. The effect of ATP- $\gamma S$ was mimicked by latrunculin A (Fig. 4), suggesting that proper actin polymerization is involved in vesicle recruitment, which needs ATP hydrolysis. With ATP- $\gamma \mathrm{S}$ and latrunculin A, the time course of release was similar to that under control conditions, when the same presynaptic $\mathrm{Ca}^{2+}$ influx was elicited. This suggests that $\mathrm{Ca}^{2+}$ regulation at the release site and, more importantly, the final steps of vesicle fusion are not impaired. In contrast, NEM and stauropsorine had no effects on the vesicle recruitment, suggesting that NSF and protein kinases are not involved. The results will impose constraints for the modeling of molecular mechanisms of secretion at synapses.

\section{Roles of NSF and protein kinases in vesicle recruitment}

It has been proposed that ATP hydrolysis is necessary for recruitment of synaptic vesicles to the releasable pool (Parsons et al., 1995; Heidelberger, 1998; Xu et al., 1998). Consistent with this, hydrolysis of ATP is involved in recruitment of synaptic vesicles at the calyx synapse. It has been suggested that ATP hydrolysis is necessary for NSF action (Parsons et al., 1995; Xu et al., 1999). We were unable to mimic the effect of ATP- $\gamma S$ by NEM (Fig. 3). This is unexpected, given the established role of NSF in the sustained component of secretion in neuroendocrine cells (Eliasson et al., 1997; Xu et al., 1999); however, the roles of NSF in synapses are controversial. For example, Schweizer et al. (1998) showed that NSF is involved in supporting rapid kinetics of transmitter release in squid giant synapses. In some synapses, it has been shown that NEM increases the frequency of spontaneous fusion events (Morishima et al., 1997). The roles of NSF in exocytosis and vesicle cycling require further studies using molecular tools such as peptide inhibitors and antibodies.

In some studies, it has been shown that protein kinases are involved in vesicle mobility (Kraszewski et al., 1996; Becherer et al., 2001) and recruitment of secretory granules can be modulated by protein kinase C (Gillis et al., 1996; Smith et al., 1998). In the present study, staurosporine, a general kinase inhibitor, did not affect recovery kinetics of the synaptic vesicles at the calyx of 
Held. It is therefore unlikely that the effect of ATP- $\gamma S$ is caused by activation of protein kinases. Phorbol esters, activators of protein kinase $\mathrm{C}$, seem ineffective in modulating the recovery from vesicle pool depletion at the calyx synapse ( $\mathrm{Wu}$ and $\mathrm{Wu}, 2001$ ), although activation of PKC and the actin cytoskeleton are somehow related (Saitoh et al., 2001).

\section{Roles of actin in vesicle recruitment}

Fewer studies have been made regarding the presynaptic role of actin, although actin has been shown to be an important constituent of the presynaptic terminal (Fifkova and Delay, 1982; Hirokawa et al., 1989) and the active zones (Phillips et al., 2001). At synapses, physiological studies have postulated that actin has important roles in vesicle mobilization (Bernstein and Bamberg, 1989; Wang et al., 1996; Kuromi and Kidokoro, 1998). On the other hand, some reports have shown that vesicle cycling is not disturbed by actin depolymerization (Betz and Henkel, 1994; Job and Lagnado, 1998; Morales et al., 2000; Li and Murthy, 2001). Positive results relied mainly on the observation that actin depolymerization changed the steady-state level of transmission during high-frequency stimulus trains and recovery from synaptic depression. At the calyx synapse, neither presynaptic $\mathrm{Ca}^{2+}$ influx nor the time course of quantal release was affected by latrunculin A (Figs. 1, 4). The only marked effect was a slowdown in the recovery from synaptic depression. We did not observe significant changes in the time course of release, which suggests that release probability is not modulated by actin depolymerization in contrast to hippocampal cultures (Morales et al., 2000). Because the effect of ATP- $\gamma S$ could be mimicked by latrunculin A (Fig. $4 E$ ), a deficit in actin polymerization alone (which requires ATP) is sufficient to explain the results obtained with ATP- $\gamma \mathrm{S}$.

How does the synapse achieve its high rate of vesicle recruitment (Fig. 1) and which role does actin play? One possibility is that vesicles after exocytosis may close the fusion pore and stay at the plasma membrane and are reused rapidly, as has been suggested in hippocampal cultures (Pyle et al., 2000). This is not likely in our experimental conditions, because capacitance measurements have shown that endocytosis takes place with a time course of several seconds after long-lasting step depolarizations at the calyx of Held (Sun and Wu, 2001; Sun et al., 2002). Our presynaptic pipette contained $0.5 \mathrm{~mm}$ EGTA, which was found to be necessary to separate the two components of release. One may argue that endocytosis does not take place accurately in our experimental conditions, because endocytosis is $\mathrm{Ca}^{2+}$ sensitive (von Gersdorff and Matthews, 1994; Neves et al., 2001). This is unlikely, because endocytosis at the calyx synapse is $\mathrm{Ca}^{2+}$ independent (Sun et al., 2002). Actin is known to play an important role in endocytosis (for review, see Brodin et al., 2000; Qualmann et al., 2000), and we cannot exclude entirely the possibility that inhibition of endocytosis may slow down the recruitment of new synaptic vesicles or simply disturb active zones.

Another possibility is that new vesicles are recruited and primed rapidly. In neuroendocrine cells, it has been shown that actin is important for the mobility of secretory granules and that stabilizers of actin filaments impede vesicle movement (Lang et al., 2000; Oheim and Stühmer, 2000). At the calyx of Held, phalloidin alone had no effects on recovery (Fig. 6). Large granules in secretory cells may need a reorganization of the actin network to be transported properly, whereas this is not necessary in the case of small clear vesicles. Rather, an intact actin network may be important for guiding synaptic vesicles toward the plasma membrane, and other proteins may assist mobilization. The calyx of Held has $\sim 600$ active zones, and each active zone has three to five vesicles within $20 \mathrm{~nm}$ from the plasma membrane (Sätzler et al., 2002). The total number of such vesicles in the whole terminal (3000 vesicles) matches quite well with the size of physiologically identified releasable vesicles (Sakaba and Neher, 2001b,c). In addition, each active zone has a total of 50 vesicles, 5-10 of which are located within $40 \mathrm{~nm}$ from the plasma membrane (Sätzler et al., 2002). The latter ones should be available for docking within $50 \mathrm{msec}$ given the speed of vesicle approach, as measured by Zenisek et al. (2000). Clustering of synaptic vesicles at the active zones therefore may contribute to the rapid recruitment that we observed here (Rowland et al., 2000). It is possible that fusion of slowly releasing vesicles takes place outside the active zone, as has been demonstrated directly in retinal bipolar cells (Zenisek et al., 2000).

As has been discussed above, we prefer an explanation for the rapid recruitment of vesicles observed at the calyx synapse that does not invoke rapid reuse of synaptic vesicles (Pyle et al., 2000) or rapid endocytosis (Sun et al., 2002). In our view, the rapid recruitment observed here is most consistent with a classic model of a reserve pool-releasable pool maturation model (Elmquist and Quastel, 1965; Rosenmund and Stevens, 1996). Consistent with this, the steady state during high-frequency stimulation and recovery from synaptic depression is shown to be actin sensitive in some synapses (Kuromi and Kidokoro, 1998; Cole et al., 2000). On the other hand, the steady state achieved during synaptic depression at the calyx of Held cannot be explained by a classic reserve pool-releasable pool model (Weis et al., 1999; Wu and Borst, 1999) (see also Betz, 1970). Thus, comparison between the vesicle pool schemes on the basis of strong stimuli and actionpotential train requires careful analysis and interpretation.

Many proteins are considered to be related to the actin filaments, such as synapsins, myosins, spectrin, and GTPases (for review, see Doussau and Augustine, 2000). Future experiments should address the molecular mechanisms of vesicle recruitment using more specific probes for such molecules.

\section{Parallel pool hypothesis and maturation hypothesis}

Previous studies failed to discriminate whether fast vesicles are converted from slow ones or, alternatively, whether both sets of vesicles are recruited in parallel (Sakaba and Neher, 2001c). In this study, latrunculin A and ATP- $\gamma \mathrm{S}$ affected both the first and second components of release (Figs. 2, 4). The simplest explanation for this is that the fast vesicles are converted from slow ones by a maturation process. In this scheme, actin is involved only in the recruitment of synaptic vesicles to the slowly releasing pool, which mediates the second component of release. However, we cannot exclude the possibility that both types of vesicles are recruited in parallel and actin and ATP operate on both pathways in a similar manner. Nevertheless, one would not expect to observe a longer delay of recovery of the fast vesicles after slowdown of the recovery of the slowly releasing vesicles in the case of a parallel recruitment scheme. Furthermore, release of the fast vesicles as well as their recruitment is sensitive to modulation by second messengers (cAMP and calmodulin) (Sakaba and Neher, 2001a, c), whereas slowly releasing vesicles are not affected by these signaling pathways. This again is consistent with the hypothesis that the fast vesicles have to go through elaborate molecular reactions during their maturation.

Although we prefer the model that slowly releasing vesicles are immature vesicles that then are converted into rapidly releasing ones, our experiments provide little information on the question of why matured vesicles release faster. The difference may be attributable to a difference in the intrinsic speed of the secretory 
apparatus (Voets, 2000) or a difference in distances from $\mathrm{Ca}^{2+}$ channels (Voets et al., 1999), or possibly to both effects, as described in adrenal chromaffin cells. In retinal bipolar cells, synaptic vesicles within active zones fuse faster than those outside active zones (Zenisek et al., 2000), because many vesicles outside active zones are newly recruited, and possibly presynaptic $\mathrm{Ca}^{2+}$ channels are concentrated at the active zone (Mennerick and Matthews, 1996; Heidelberger, 1998; Burrone and Lagnado, 2000). This issue should be addressed in the near future.

\section{References}

Acharya JK, Labarca P, Delgado R, Jalink K, Zuker CS (1998) Synaptic defects and compensatory regulation of inositol metabolism in inositol polyphosphate 1-phosphatase mutants. Neuron 20:1219-1229.

Beaumont V, Zhong N, Froemke RC, Ball RW, Zucker RS (2002) Temporal synaptic tagging by $\mathrm{I}_{\mathrm{h}}$ activation and actin: involvement in long-term facilitation and cAMP-induced synaptic enhancement. Neuron 33:601-613.

Becherer U, Guatimosim C, Betz WJ (2001) Effects of staurosporine on exocytosis and endocytosis at frog motor nerve terminals. J Neurosci 21:782-787.

Bernstein BW, Bamberg JR (1989) Cycling of actin assembly in synaptosomes and neurotransmitter release. Neuron 3:257-265.

Betz WJ (1970) Depression of transmitter release at the neuromuscular junction of the frog. J Physiol (Lond) 206:629-644.

Betz WJ, Henkel AW (1994) Okadaic acid disrupts clusters of synaptic vesicles in frog motor nerve terminals. J Cell Biol 124:843-854.

Borges S, Gleason E, Turelli M, Wilson M (1995) The kinetics of quantal transmitter release from retinal amacrine cells. Proc Natl Acad Sci USA 92:6896-6900.

Borst JGG, Sakmann B (1996) Calcium influx and transmitter release in a fast CNS synapse. Nature 383:431-434.

Borst JGG, Helmchen F, Sakmann B (1995) Pre- and postsynaptic wholecell recordings in the medial nucleus of the trapezoid body of the rat. J Physiol (Lond) 489:825-840.

Brodin L, Löw P, Shupliakov O (2000) Sequential steps in clathrinmediated synaptic vesicle endocytosis. Curr Opin Neurobiol 10:312-320.

Burrone J, Lagnado L (2000) Synaptic depression and the kinetics of exocytosis in retinal bipolar cells. J Neurosci 15:568-578.

Charlton MP, Smith SJ, Zucker RS (1982) Role of presynaptic calcium ions and channels in synaptic facilitation and depression at the squid giant synapse. J Physiol (Lond) 323:173-193.

Christensen BN, Martin AR (1970) Estimates of probability of transmitter release at the mammalian neuromuscular junction. J Physiol (Lond) 210:933-945.

Cole JC, Villa BRS, Wilkinson RS (2000) Disruption of actin impedes transmitter release in snake motor terminals. J Physiol (Lond) 525:579-586.

Cooper JA (1987) Effects of cytochalasin and phalloidin on actin. J Cell Biol 105:1473-1478.

Dittman JS, Regehr WG (1998) Calcium dependence and recovery kinetics of presynaptic depression at a fast central synapse. J Neurosci 18:6147-6162.

Dobrunz LE, Stevens CF (1997) Heterogeneity of release probability, facilitation, and depletion at central synapses. Neuron 18:995-1008.

Doussau F, Augustine GJ (2000) The actin cytoskeleton and neurotransmitter release: an overview. Biochimie 82:353-363.

Eliasson L, Renström E, Ding W-G, Proks P, Rorsman P (1997) Rapid ATPdependent priming of secretory granules precedes $\mathrm{Ca}^{2+}$-induced exocytosis in mouse pancreatic B-cells. J Physiol (Lond) 503:399-412.

Elmquist D, Quastel DMJ (1965) A quantitative study of end-plate potentials in isolated human muscle. J Physiol (Lond) 178:505-529.

Fifkova E, Delay RJ (1982) Cytoplasmic actin in neuronal processes as a possible mediator of synaptic plasticity. J Cell Biol 95:345-350.

Forsythe ID (1994) Direct patch recording from identified presynaptic terminals mediating glutamatergic EPSCs in the rat CNS, in vitro. J Physiol (Lond) 479:381-387.

Gillis KD, Mossner R, Neher E (1996) Protein kinase C enhances exocytosis from chromaffin cells by increasing the size of the readily releasable pool of secretory granules. Neuron 16:1209-1220.

Gomis A, Burrone J, Lagnado L (1999) Two actions of calcium regulate the supply of releasable vesicles at the ribbon synapse of the retinal bipolar cells. J Neurosci 19:6309-6317.
Heidelberger R (1998) Adenosine triphosphate and the late steps in calcium-dependent exocytosis at a ribbon synapse. J Gen Physiol 111:225-241.

Heidelberger R, Sterling P, Matthews G (2002) Roles of ATP in depletion and replenishment of the releasable pool of synaptic vesicles. J Neurophysiol 88:98-106.

Helmchen F, Borst JGG, Sakmann B (1997) Calcium dynamics associated with a single action potential in a CNS presynaptic terminal. Biophys J 72:1458-1471.

Hessler NA, Shirke AM, Malinow R (1993) The probability of transmitter release at a mammalian central synapse. Nature 366:569-572.

Hirokawa N, Sobue K, Kanda K, Harada A, Yorifuji H (1989) The cytoskeletal architecture of the presynaptic terminal and molecular structure of synapsin I. J Cell Biol 108:111-126.

Job C, Lagnado L (1998) Calcium and protein kinase C regulate the actin cytoskeleton in the synaptic terminal of retinal bipolar cells. J Cell Biol 143:1661-1672.

Kim C-H, Lisman JE (1999) A role of actin filaments in synaptic transmission and long-term potentiation. J Neurosci 18:4314-4324.

Kraszewski K, Daniell L, Mundigl O, DeCamilli P (1996) Mobility of synaptic vesicles in nerve endings monitored by recovery from photobleaching of synaptic vesicle-associated fluorescence. J Neurosci 16:5905-5913.

Kuromi H, Kidokoro Y (1998) Two distinct pools of synaptic vesicles in single synaptic boutons in a temperature-sensitive Drosophila mutant, shibire. Neuron 20:917-925.

Lang T, Wacker I, Wunderlich I, Rohrbach A, Giese G, Soldtai T, Almers W (2000) Role of actin cortex in the subplasmalemmal transport of secretory granules in PC-12 cells. Biophys J 78:2863-2877.

Li Z, Murthy VN (2001) Visualizing postendocytic traffic of synaptic vesicles at hippocampal synapses. Neuron 31:593-605.

Mennerick S, Matthews G (1996) Ultrafast exocytosis elicited by calcium current in synaptic terminals of retinal bipolar neurons. Neuron 17:1241-1249.

Morales M, Colicos MA, Goda Y (2001) Actin-dependent regulation of neurotransmitter release at a central synapse. Neuron 27:539-550.

Morishima W, Kirov SA, Pitler TA, Martin LA, Lenz RA, Alger BE (1997) $\mathrm{N}$-ethylmaleimide blocks depolarization-induced suppression of inhibition and enhances GABA release in the rat hippocampal slice in vitro. J Neurosci 17:941-950.

Moser T, Beutner D (2000) Kinetics of exocytosis and endocytosis at the cochlea inner hair cell afferent synapse of the mouse. Proc Natl Acad Sci USA 97:883-888.

Murthy VN, Sejnowski TJ, Stevens CF (1997) Heterogeneous release probabilities of visualized individual hippocampal synapses. Neuron 18:599-612.

Neher E, Sakaba T (2001a) Combining deconvolution and noise analysis for the estimation of transmitter release rates at the calyx of Held. J Neurosci 21:444-461.

Neher E, Sakaba T (2001b) Estimating transmitter release rates from postsynaptic current fluctuations. J Neurosci 21:9038-9054.

Neves G, Gomis A, Lagnado L (2001) Calcium influx selects the fast mode of endocytosis in the synaptic terminal of retinal bipolar cells. Proc Natl Acad Sci USA 97:15282-15287.

Oheim M, Stühmer W (2000) Tracking chromaffin granules on their way through the actin cortex. Eur Biophys J 29:67-89.

Parsons TD, Coorssen JR, Horstmann H, Almers W (1995) Docked granules, the exocytotic burst, and the need for ATP hydrolysis in endocrine cells. Neuron 15:1085-1096.

Phillips GR, Huang JK, Wang Y, Tanaka H, Shapiro L, Zhang W, Shan WS, Arndt K, Frank M, Gordon RE, Gawinowicz MA, Zhao Y, Colman DR (2001) The presynaptic particle web: ultrastructure, composition, dissolution, and reconstitution. Neuron 32:63-77.

Pyle JL, Kavalali ET, Piedras-Renteria ES, Tsien RW (2000) Rapid reuse of readily releasable vesicles at hippocampal synapses. Neuron 28:221-231.

Qualmann B, Kessels MM, Kelly RB (2000) Molecular links between endocytosis and the actin cytoskeleton. J Cell Biol 150:F111-F116.

Rosenmund C, Stevens CF (1996) Definition of the readily releasable pool of vesicles at hippocampal synapses. Neuron 16:1197-1207.

Rosenmund C, Clements JD, Westbrook GL (1993) Nonuniform probability of glutamate release at a hippocampal synapse. Science 262:754-757.

Rowland KC, Irby NK, Spirou GA (2000) Specialized synapse-associated structures within the calyx of Held. J Neurosci 20:9135-9144. 
Saitoh N, Hori T, Takahashi T (2001) Activation of the epsilon isoform of protein kinase $\mathrm{C}$ in the mammalian nerve terminal. Proc Natl Acad Sci USA 98:14017-14021.

Sakaba T, Neher E (2001a) Preferential potentiation of fast-releasing synaptic vesicles by cAMP at the calyx of Held. Proc Natl Acad Sci USA 98:331-336.

Sakaba T, Neher E (2001b) Quantitative relationship between transmitter release and calcium current at the calyx of Held synapse. J Neurosci 21:462-476.

Sakaba T, Neher E (2001c) Calmodulin mediates rapid recruitment of fastreleasing synaptic vesicles at a calyx-type synapse. Neuron 32:1119-1131.

Sampath P, Pollard TD (1991) Effects of cytochalasin, phalloidin, and pH on the elongation of actin filaments. Biochemistry 30:1973-1980.

Sätzler L, Lübcke J, Söhl K, Borst JGG, Bollmann J, Frotscher M, Sakmann B (2002) Three-dimensional reconstruction of a calyx of Held and its postsynaptic principal neuron in the medial nucleus of the trapezoid body. J Neurosci 22:10567-10579.

Schneggenburger R, Meyer AC, Neher E (1999) Released fraction and total size of a pool of immediately available transmitter quanta at a calyx synapse. Neuron 23:399-409.

Schweizer FE, Dresbach T, DeBello WM, O’Connor V, Augustine GJ, Betz H (1998) Regulation of neurotransmitter release kinetics by NSF. Science 279:1203-1206.

Smith C, Moser T, Xu T, Neher E (1998) Cytosolic Ca ${ }^{2+}$ acts by two separate pathways to modulate the supply of release-competent vesicles in chromaffin cells. Neuron 20:1243-1253.

Spector I, Braet F, Shochet NR, Bubb MR (1999) New anti-actin drugs in the study of the organization and function of the actin cytoskeleton. Microsc Res Tech 47:18-37.

Stevens CF, Wesseling JF (1998) Activity-dependent modulation of the rate at which synaptic vesicles become available to undergo exocytosis. Neuron 21:415-424.

Sun JY, Wu LG (2001) Fast kinetics of exocytosis revealed by simultaneous measurements of presynaptic capacitance and postsynaptic currents at a central synapse. Neuron 30:171-182.

Sun LY, Wu XS, Wu LG (2002) Single and multiple vesicle fusion induce different rates of endocytosis at a central synapse. Nature 417:555-559.

Swandulla D, Hans M, Zipser K, Augustine GJ (1991) Role of residual calcium in synaptic depression and posttetanic potentiation: fast and slow calcium signaling in nerve terminals. Neuron 7:915-926.
Takahashi N, Kadowaki T, Yazaki Y, Ellis-Davies GCR, Miyashita Y, Kasai H (1999) Post-priming actions of ATP on $\mathrm{Ca}^{2+}$-dependent exocytosis in pancreatic beta cells. Proc Natl Acad Sci USA 96:760-765.

Voets T (2000) Dissection of three $\mathrm{Ca}^{2+}$-dependent steps leading to secretion in chromaffin cells from mouse adrenal slices. Neuron 28:537-545.

Voets T, Neher E, Moser T (1999) Mechanism underlying phasic and sustained secretion in chromaffin cells from mouse adrenal slices. Neuron 23:607-615.

von Gersdorff H, Matthews G (1994) Inhibition of endocytosis by elevated internal calcium in a synaptic terminal. Nature 370:652-655.

von Gersdorff H, Matthews G (1997) Depletion and replenishment of vesicle pools at a ribbon-type synaptic terminal. J Neurosci 17:1919-1927.

von Gersdorff H, Schneggenburger R, Weis S, Neher E (1997) Presynaptic depression at a calyx synapse: the small contribution of metabotropic glutamate receptors. J Neurosci 17:8134-8146.

Walmsley B, Edwards FR, Tracey DJ (1988) Non-uniform release probabilities underlie quantal synaptic transmission at a mammalian excitatory central synapse. J Neurophysiol 60:889-908.

Wang LY, Kaczmarek LK (1998) High-frequency firing helps replenish the readily releasable pool of synaptic vesicles. Nature 394:384-388.

Wang XH, Zheng JQ, Poo MM (1996) Effects of cytochalasin treatment on short-term synaptic plasticity at developing neuromuscular junctions in frogs. J Physiol (Lond) 491:187-195.

Weis S, Schneggenburger R, Neher E (1999) Properties of a model of $\mathrm{Ca}^{2+}$. dependent vesicle pool dynamics and short term synaptic depression. Biophys J 77:2418-2429.

Wu LG, Borst JGG (1999) The reduced release probability of releasable vesicles during recovery from short-term synaptic depression. Neuron 23:821-832.

Wu XS, Wu LG (2001) Protein kinase C increases the apparent affinity of the release machinery by enhancing the release machinery downstream of the $\mathrm{Ca}^{2+}$ sensor. J Neurosci 21:7926-7936.

Xu T, Binz T, Niemann H, Neher E (1998) Multiple kinetic components of exocytosis distinguished by neurotoxin sensitivity. Nat Neurosci $1: 192-200$.

$\mathrm{Xu}$ T, Ashery U, Burgoyne RD, Neher E (1999) Early requirement for a-SNAP and NSF in the secretory cascade in chromaffin cells. EMBO J 18:3293-3304.

Zenisek D, Steyer JA, Almers W (2000) Transport, capture and exocytosis of single synaptic vesicles at active zones. Nature 406:849-854. 